\title{
Sidewalk Accessibility and Pedestrian Safety among Students with Physical Disability in the University of Cape Coast
}

\author{
PRINCE KWAME ODAME* and REGINA OBILIE AMOAKO-SAKYI
}

Department of Geography and Regional Planning, Cape Coast, Ghana, West Africa.

\begin{abstract}
In pursuance of the UN's Convention on the Right of Persons with Disability and Ghana's disability act, the University of Cape Coast has equally instituted a string of interventions to ensure equitable access to its facilities to all students regardless of one's disability. Emphasis on this has however focused on the modification and inclusion of disability accessories in the construction of new facilities as well as the enactment of disability inclined policies related to admission, residential status and others aspect of campus life. One key area that has not received much attention has been the nature of campus walking environment and how it promotes easy mobility among all students' groups. To assess the nature of campus walking environment, the study employed the use of an accessibility auditing scheme and also engaged 30 visually impaired and one wheelchair user who were reached through snowballing. An in-depth interview guide was used as the primary data collection instrument for the qualitative study. The study found that the absence of walkway in some high pedestrian traffic areas, discontinuity of sidewalk and path obstructing objects were key factors that reduced the ease with which students with disability use sidewalk on campus. The study recommends an overhauling of the current walking environment as well as enforcement of state and international policy regarding the development of an inclusive environment.
\end{abstract}

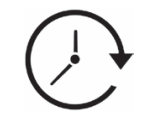

Article History

Received: 4 December 2019

Accepted: 30 December 2019

\section{Keywords}

Disability;

Sidewalk;

University Of Cape Coast;

Visually Impaired;

Wheelchair;

Zebra Crossing.

\section{Introduction}

Walking constitutes an essential part of human life and for persons with disability, this activity may not come at the same ease, since the design and construction of the physical environment including tertiary institutions may not meet their mobility needs (Danso, Ashigbi, \& Tudzi, 2014; Eseta, 2017). To Danso, Ashigbi and Tudzi, mobility

CONTACT Prince Kwame Odame $\$ pkodame@gmail.com 9 Department of Geography and Regional Planning, Cape Coast, Ghana, West Africa.

\section{(c) (i)}


can best be described in terms of one's ability to walk independently and freely. By extension, walking is considered as a prerequisite to the attainment of daily living activities including attending lectures, visiting the library and other places of interest in a university (Ashigbi, Danso, Dogbevi, \& Owusu-Dabo, 2013). While identifying the role of walking to ones' quality of life, Frye (2013) reiterates the need for a safe and conducive walking environment that offers equal opportunities for all users irrespective of ones demographic or physical characteristics. By this, the presence of sidewalks does not only offer an exclusive right of passage for persons with disability across the globe but also protect pedestrians from road crashes and offer the opportunity to enjoy the aesthetics of the environment (Brown, Werner, Amburgey, \& Szalay, 2007; Litman, 2019).

The call to modify the physical environment can be traced to the proponent of the social model of disability who argues that unnecessary barriers in the physical environment and society's poor understanding of varying functional ability are rather the factors that limit activity participation and excludes persons with disability (PWD) from enjoying mainstream activities (Anastasiou \& Kauffman, 2013; Haegele \& Hodge, 2016; Lang, 2007). Consistent with this definition, the emphasis on medical rehabilitation, the establishment of institutional asylums and other forms of segregator treatments were discouraged since disability was no longer deemed an inherent characteristic of an individual but rather seen in the society in which one lives (Ocran, 2019). Following the declaration of the Convention on the Rights of Persons with Disability, the United Nations' openly called for the removal of all barriers to PWDs accessibility including those in the walking environment (United Nations, 2006). This declaration was signed by Ghana in 2007 but prior to this signatory, Ghana had already enacted its national disability policy in 2006 (Adjei, 2013).

While offering a legal framework for the protection of the rights of PWDs in Ghana, a review of Ghana's disability act highlights the country's intention to ensure equal usage and access to public facilities like the University of Cape Coast regardless of one's disability, creed or economic status (Adjei, 2013). For instance, section 6 of this Act enjoins all owners or managers of such public facilities to ensure that all facets of their properties are made barrier-free to persons with disability. Additionally, section 23 to 30 also highlights the need for the removal of such barriers in the transport environment (Government of Ghana, 2006).

In Addo (2014)'s view, the call for the removal of barriers to mobility in schools (the physical environment) as proposed by both the proponents of the social model of disability and Convention on the Rights of Person With Disability also conforms to the Salamanca Statement on how the removal of barriers in all sections of educational facilities can promote inclusive education for all (United Nations Educational Social and Cultural Organisation, 1994). Being the first tertiary institution to be established in the Central region by Ghana's first president, the University of Cape Coast has enacted its own disability policy that spells out a series of interventions intended to improve mobility and access to all educational facilities for its 18,949 regular students, including students with disability (University of Cape Coast, 2016). Principal among these interventions is the lowering of the entry requirement for students with disability, the inclusion of disability-friendly accessories in the construction of new buildings, the cluster of some facilities in certain sections of campus as well as policies related to students' residential status. With regards to residential status, the University of Cape Coast guarantees accommodation for students with disability throughout their four-year undergraduate studies while students who do not identify with any impairments are only assured accommodation for their first year in any of the hostels managed by the University. While such interventions can only be enjoyed on reaching facilities like the library, lecture theatre and hostel, one question that fueled this study was the condition of the walkways that links students to these facilities.

Very little documentation on mobility and transport issues for students with disability was observed, however, the University management has made attempts to offer free ridership on all of its shuttle services on campus. Though the campus shuttle services entail some level of private sector participation, such free ridership was also extended to students who identify with a disability. Unfortunately, this free ridership was not even stipulated in the 
University's disability policy neither is it found in the student's handbook nor other documents perused at the time of this study. In the face of this free ridership, other factors like the dispersed layout of educational and students residential facilities, fixed routes of campus shuttles, long queues during peak times as well as the absence of shuttles at night and on weekends, induces students to resort to walking as the most available alternative. The decision to settle for walking is also informed by that fact that alternative transport services like 'taxis' charge more than twice the cost of campus shuttles. Additionally, taxis do not offer free ridership to students with disability, since the University management does not have direct control over their operations.

For students with disability, a barrier laden walking environment that is saddled with poor path conditions, discontinued sidewalk, presence of obstacles, absence of disability-friendly accessories like curb cuts and tactile signage, may prolong time used in reaching campus facilities or even reduce the desirability of social and non-academic activities, which are critical to quality of life on campus (Bezyak, Sabella, \& Gattis, 2017; Mitchell \& Rickert, 2010). Unfortunately, efforts geared towards improving the lives of students with disability on campus have rather focused on the retrofitting of various destinations and improvement of the design of facilities on campus, leaving the walking space that constitutes a crucial part of students daily activities. Also, Ghana's Disability Act's 10-year moratorium for the removal of barriers in the physical environment elapsed in 2016, giving room to examine the extent to which the University of Cape Coast walking environment promotes safe and inclusive mobility (Adjei, 2013). In addition to the introduction, the study is divided into five (5) sections: section two highlight the methodology while the result and discussion, as well as conclusion, are presented in section four and five respectively.

\section{Methods}

Among the topical issues relating to students with disability, their use of walking spaces has received little attention, since local studies have rather focused on their accessibility or usage of key destinations like lecture theatres and hospitals (Adams, 2012; Ashigbi, Danso, Tudzi, \& Torgbenu, 2017; Danso, Atuahene, \& Agyekum, 2017; Danso,
Ayarkwa, \& Dansoh, 2009; Tudzi, Bugri, \& Danso, 2017). In view of the above, this study adopted an exploratory research design, since it affords the opportunity to acquire new insights, discover new ideas, as well as expand knowledge on new and existing phenomena including the mobility needs and constraints of students with physical disability in the University of Cape Coast (Odame, 2017).

While focusing on the nature and condition of the walk spaces on campus, the study adopted an access audit, which establishes the performances of campus walking space with regards to an already established standard, as prescribed by the UNDP's International Best Practice in Accessible Public Transportation for Persons with Disabilities (Mitchell \& Rickert, 2010). The choice of an access audit depends on the type of impairment under review, facility and corresponding accessories in the said facility. For instance, the Universal Mobility Index (UMI) was adopted as an accessibility approach in Melbourne (Australia) to measure PWDs perception on accessible areas of their general environment using binary numerals (Green, 2011). Based on PWDs' ratings of their perceived ease in using various sections of the environment, an aggregated index was developed to offer a good summary of PWDs perceptions of their ease in reaching or using various facilities of their environment. Unlike the use of Binary numerals in the UMI, Adam (2019) employed the United Nations World Tourism Organization (UNWTO)'s recommendation to examine the presence of identified disability-friendly accessories like parking signage, tactile signage and ramps in selected hotels in Ghana.

While relying on the UNDP's International Best Practice in Accessible Public Transportation for Persons with Disabilities, an auditing scheme was developed to examined the presence, conditions and dimension of sidewalks which also included the inspection of walking facilities like curb, curb cuts, tactile signage, width of sidewalk as well as crossing aids for students with disability. To execute this, principal walkways on campus were segmented into 100-meter stretches. As employed in a child walkability study in the Cape Coast Metropolitan Assembly in Ghana (Amoako-Sakyi, 2016), a 100 metre was deemed relatively short to observe and take an accurate reading of all indicators on a 
segment. Secondly, the study sought to produce a detailed assessment of each segment, hence anything greater than a hundred metre might translate to the aggregation of indicators. In all, 58 segments from both the North and South campus were accessed for study as seen in Plate 1.
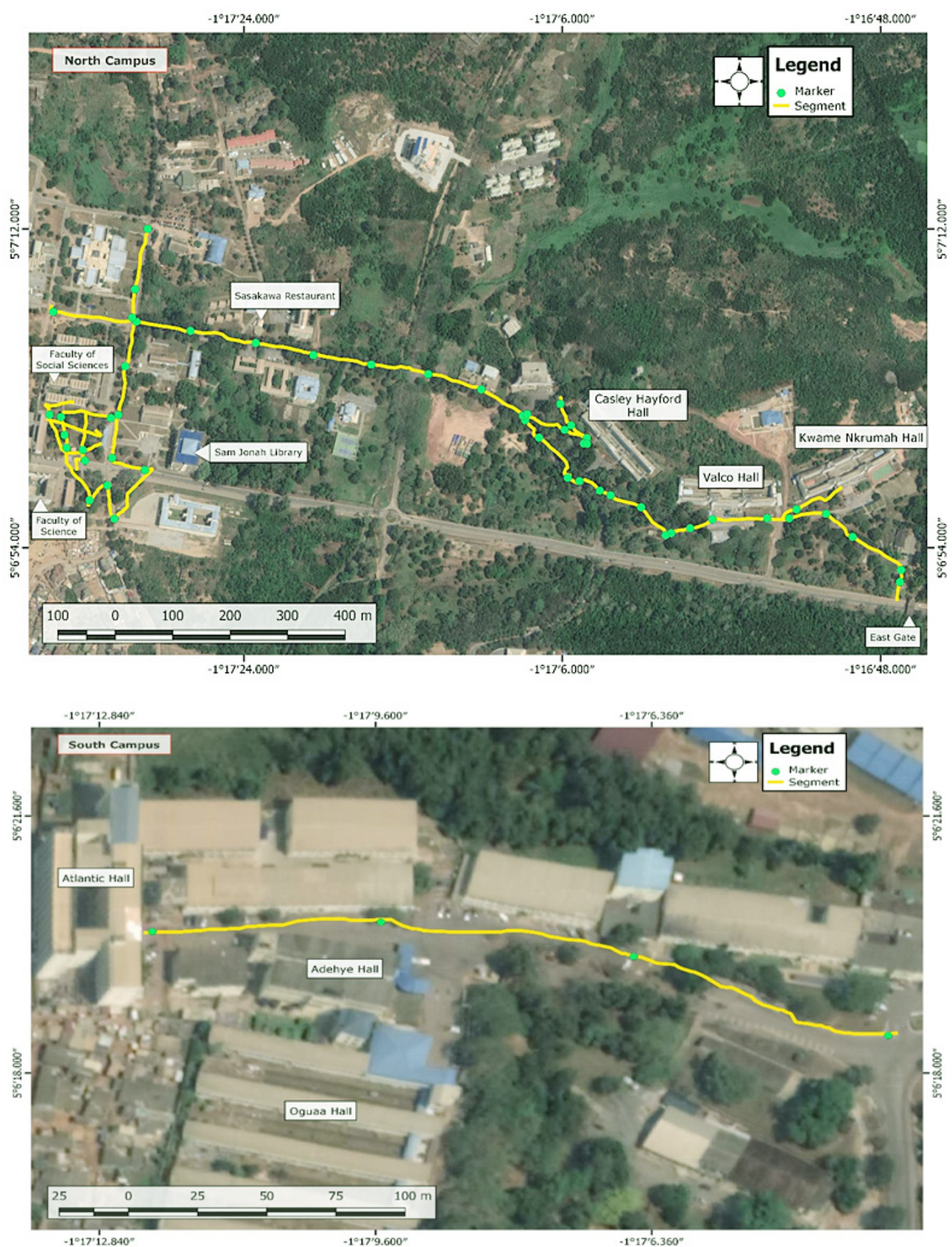

Plate 1: Segment accessed in the North and South Campus

Source: Fieldwork, 2019 
In demarcating the 100-metre mark, the study employed the use of 'my tracks', an android based mobile phone application that allows users to plan their trip when commuting from one point to the other. In using the University's East gate (one of the main entry points to the campus) as a starting point, the mobile phone application allowed the researcher to map out every route that was used for the assessment and once this was done, the mobile phone application automatically demarcated the 100-metre mark across mapped-out routes. Upon reaching the 100-metre mark, the application emitted clear audible signals that would alert the researcher of his location. The use of this application further reduced the tendency of duplicating assessment on any particular route since the application clearly provided a colour coding that helped to differentiate covered distances from the ones that had not been covered.

In addition to the use of the auditing scheme, the study also relied on qualitative data which was based on the lived experiences of 30 visually impaired and one wheelchair user as they used current walkways on campus. The choice for the target population was informed by the reason that this disability group constitutes most visible forms of disability on campus, occupy about $60 \%$ of Ghana's disability population and also constitute the largest disability group on campus (Ghana Statistical Service, 2014b). These students were reached by use of snowballing given the parse layout of campus and busy schedule of students. In all, an in-depth interview was used as a primary data collection instrument since it offers the best response rate among respondents with disability. The use of an in-depth interview was deemed necessary since it afforded the opportunity to capture the voice of the population of interest and also add both human and social perspective to the measure of an accessible walking environment. At all levels, strict adherence to ethical principles was upheld, since it afforded the opportunity to protect respondents and uphold the integrity of the study.

\section{Results and Discussions \\ Socio-Demographic Characteristics of Respondents}

About $66.7 \%$ of respondents were males as against females who constituted only $33.3 \%$. Although the Ghana Statistical Service (2012) reveals that Ghana has more females $(52.5 \%)$ with disability than males $(47.5 \%)$, data provided by this study proved different. In accounting for the difference, Mantey (2014) observed that cultural practices and the stigma attached to bringing up children with disability contribute to the poor enrolment rate for students with disability especially at the basic level. In addition, Nyangweso (2018) opines that priority on the educational advancement of male children in the Global South equally accounts for the increasing number of males with disability in tertiary institutions as compared to females. Furthermore, more than half $(55.5 \%)$ of respondents were between the ages of 23 and 28 years, which was the average age cohort for most undergraduate students in Ghana. Aside from this age group, students within the ages of 17 to 22 years constituted $33.3 \%$ and this largely included first-year undergraduate students. Lastly on the age cohort, students within 29 to 34 years and those above 34 years constituted $7.4 \%$ and $3.7 \%$ respectively, which constituted fourthyear undergraduate and postgraduate students respectively. With reference to the accommodation status of respondents, $59 \%$ of respondents were found in the North Campus which consist of key educational and residential facilities for both students and faculty on campus as seen in Plate 1. Specifically, the three traditional halls that made up the North Campus include Casely Hayford (33.3\%), Valco (22.2\%) and Kwame Nkrumah (3.7\%) hall. On the other hand, the South Campus comprised Adehye (11.1\%), Oguaa (22.2\%) and Atlantic (7.4\%) hall. The last demographic characteristic is the type of impairment presented by respondents. The visually impaired students constituted $96.5 \%$ while wheelchair users represented only $3.5 \%$ of the total respondents. Though these two impairment types were the only disability groups that were engaged for this study, census data on Ghana also cites the visually impaired (40\%) and physically impaired $(25 \%)$ as the two leading disability types in both urban and rual areas in Ghana (Ghana Statistical Service, 2014 a). 
Table 1: Socio-demographic characteristics of the respondents

\begin{tabular}{lll}
\hline Variable & Frequency & Percentage \\
\hline Sex & & \\
Males & 18 & 66.7 \\
Females & 9 & 33.3 \\
Age & & \\
17 to 22 years & 9 & 22.2 \\
23 to 28 years & 15 & 55.5 \\
29 to 34 years & 2 & 7.4 \\
Above 34 years & 1 & 3.7 \\
Hall of residence & & \\
Casely Hayford & 9 & 33.3 \\
Valco & 6 & 22.2 \\
Kwame Nkrumah & 1 & 3.7 \\
Oguaa & 6 & 22.2 \\
Adehye & 3 & 11.1 \\
Atlantic & 2 & 7.4 \\
Type of Impairment & & \\
Visually Impaired & 28 & 96.5 \\
Mobility Impaired & 1 & 3.5 \\
\hline
\end{tabular}

Source: Fieldwork, 2016

\section{Sidewalk Presence and Condition}

Throughout the study, the most dominant observed pedestrian facility was the sidewalk, which ensured a complete separation of pedestrians from vehicles. In all, routes with a sidewalk on at least one side constituted about $80 \%$ of all segments examined which was deemed higher than the entire Cape Coast Metropolitan Assembly that had less than $7 \%$ of its roads with sidewalk as indicated by Amoako-Sakyi (2016) in a school path walkability study. Though the pedestrian sidewalk was dominant, its condition and dimension did not fully follow the prescribed dictates of an integrated transport system as cited by the UNDP (Mitchell \& Rickert, 2010). Observed sidewalk width in the University of Cape Coast ranged from 1.05 to 2 metres and this dimension conforms to UNDP's ideal sidewalk width of 1 metre in areas of limited space to 2 metres in areas with ample space. This dimension is ideal since it permits at least a wheelchair user and a non-wheelchair user to use the sidewalk at the same time without any collision. Though the width of observed sidewalks conformed to UNDP's view, not all parts of the roads on campus had sidewalks.
Sections of campus which did not have sidewalks included areas of high pedestrian traffic like the route in front of the Sasakawa hostel and the route along the University Avenue.

In recounting one's usage of a route without pavement, a Level 300 visually impaired male at the North Campus revealed that:

"It is a bit difficult because you don't know which section of the road to walk. For instance, if there were pavements, I would have used my white cane to trace the edges of the pavement while walking. Tracing the edges of the pavement would allow me to tell if I am moving off the pavement. In our current state where some roads do not have pavements, there is no way to tell if you are moving to the left or right especially when walking on the edges of the road. Sometimes, drivers toot their horns to alert me when I veer off into the main road while walking on routes without pavements. For me, it's very difficult to trace where to walk on route with no pavement"

In the wake of routes without a sidewalk, the study also found the abrupt end of sidewalks on campus as another key finding. Sidewalk discontinuity, as it is called, exposes both students with and without disability to a high risk of an accident, since the only option for pedestrians is to share the road with vehicles. From the study, sidewalk discontinuity was either the product of incomplete construction of sidewalk or the location of offices within areas of high pedestrian traffic as seen in Plate 2. Areas of modal conflicts as enumerated by respondents expose them to a high risk of injuries especially when it involves vulnerable groups like students with physical disability who are deemed to have a slower response rate to danger when compared to students without disability (Amoako-Sakyi, 2016)

For routes with pavements, the condition of these pavements plays a major role in determining the level of convenience in its usage. The basis for rating the level of convenience in using these sidewalks was on the degree of dislodged bricks, poorly fitted bricks and how even the surface was, irrespective of the path material used. Data from the field survey revealed that only $41.9 \%$ of routes with pavements on campus were rated as good and these were routes with no path obstruction, well-fitted bricks 
and even surfaced pavement. The poor and average rated routes recorded $41.9 \%$ and $16.2 \%$ respectively and these were areas with one or a combination

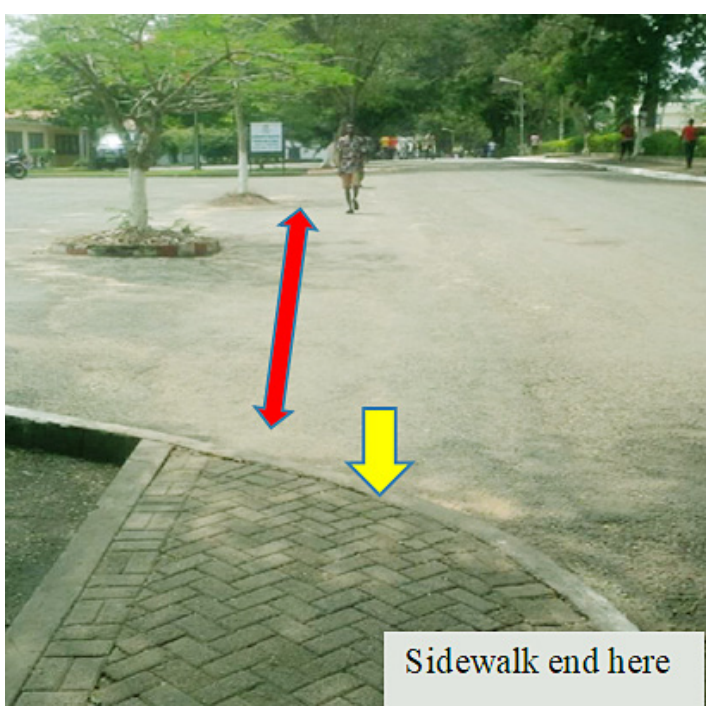

of dislodged bricks or potholes, electric poles and signage on the pavement as well as an uneven pavement surface.

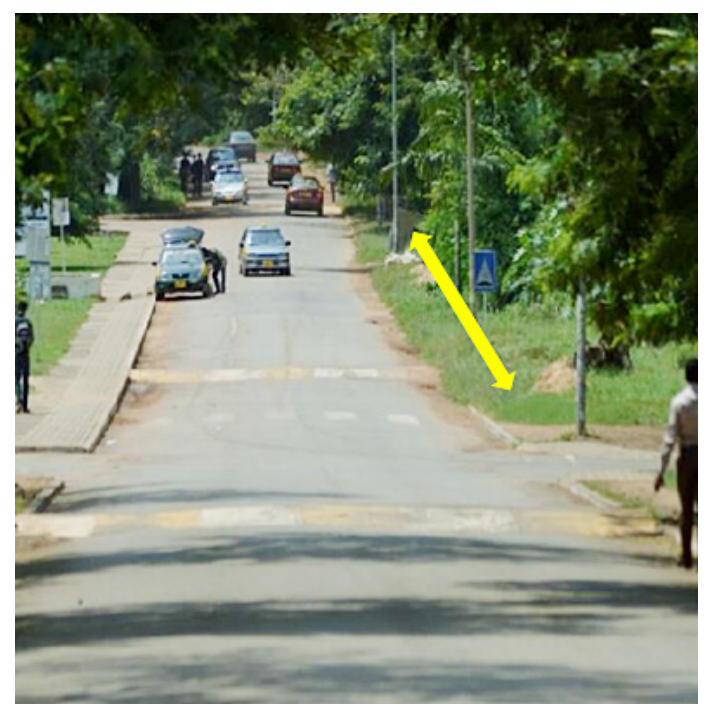

Plate 2: Discontinuity of sidewalk at Sasakawa and FELT junction

\section{Source: Fieldwork, 2016}

Data from the study further revealed that some areas with dislodged bricks as seen in Plate 3 were the product of construction or repair work across sidewalks on campus. Other areas of dislodged bricks were also as a result of poorly laid bricks which got displaced after some rains as seen in Plate 3. Evidence from the fieldwork further revealed that such a situation frustrates the movement of students

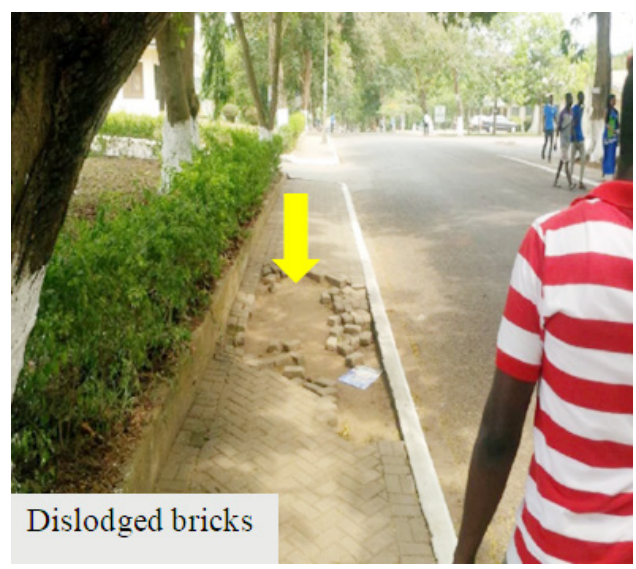

with disability since the use of such sidewalk becomes burdensome hence their least likely travel option. At a point, the study observed some visually impaired students who had to resort to the road when they got to some of the above-cited locations. Such situations hinder students with disability's access to certain services, which may easily be enjoyed by students without any form of disability.

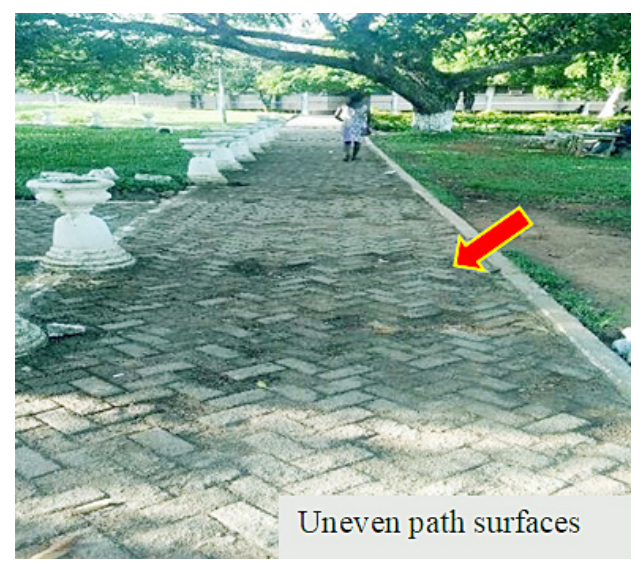

Source: Fieldwork, 2016

Plate 3: Dislodged bricks on the Sasakawa road 
In addition to the above, the presence of obstructions on the sidewalk also reduces the level of convenience and patronage of sidewalks. In Ferreira \& Sanches (2007) view, these objects obstruct the flow of traffic and influence commuter's choice of a route that presents the least obstruction or even forfeits an intended trip, if the obstructions are beyond the control of a commuter.

In recounting respondents' experience in using pavements with path obstructing objects, a Level 300 visually impaired female student from the North Campus indicated that:
"...Some of the pavement have potholes, so when you are a little distracted while walking on such pavements, you may step into stagnant water or even step in those pits, which may cause injuries. Some sections of the pavements have road signs or signposts erected in the middle of the pavement. With these ones too, if you are not aware, you may easily bump into some of them ...... and sustain some injuries....."

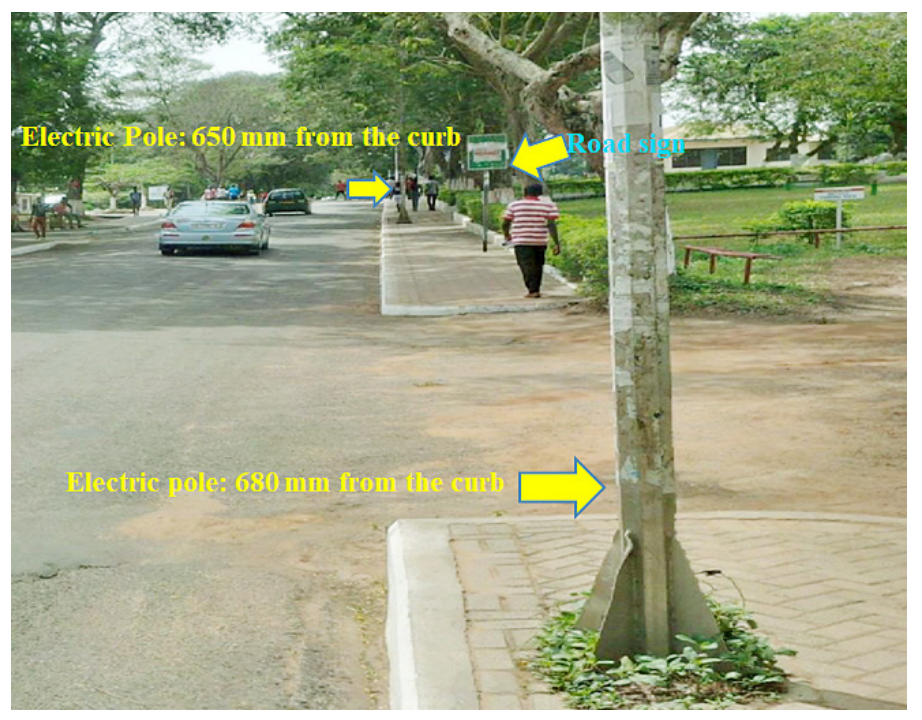

\section{Source: Fieldwork, 2016}

Plate 4: Dislodged bricks on the Sasakawa road

Following this narrative, findings from the field indicate that $52.6 \%$ of the segments recorded the presence of objects that restricted the free movement of pedestrians. Notable among these objects were streetlights, signposts, protruded tree branches or roots, dwarf walls and potholes. The position of these objects reduces the width of the sidewalk, which makes it a challenge for students with disability, especially wheelchair users. In taking measurements, the study revealed that electric poles on the average were placed 0.6 to 0.67 metres from the curb of a 2-metre sidewalk as seen in Plate 4. The loss of sidewalk space to such obstructions would either translate to competition for space in such areas or commuters resorting to the road as an alternative which further exposes students to the risk of vehicular crashes and injuries. The presence of these objects further contravenes the UNDP's recommendation for an accessible pedestrian facility, since sidewalks are expected to have a clear path without any hanging, protruding or obstructing objects. It should be noted that all these objects were not found on the same segment throughout campus.

\section{Curb and Curb Cuts}

In addition to the provision of sidewalks for all road users, the autonomy of wheelchair users, in particular, will still not be guaranteed, if complementary 
accessories like higher curbs and curb cuts are not included in the construction of sidewalks. Observations from the routes examined revealed that 20 out of 58 segments recorded curb heights, ranging from 130 to 180 millimetres. In Hoy's (2004) and McNulty's (2003) recommendation, a minimum curb height of 130 millimetres ensures the safety of road users, since this height is significant to alert any driver of a change in height if he/she accidentally or deliberately transit from the road to the pavement. For the visually impaired and the wheelchair user too, the relatively high curb offers guidelines to detect the edge of the pavement and also identifies any significant change in height as he or she moves from the pavement to the road and vice versa. The remaining 38 segments recorded curb height of less than 130 millimetres (as shown in Plate 5) and also contravens the recommendation of Hoy's (2004).

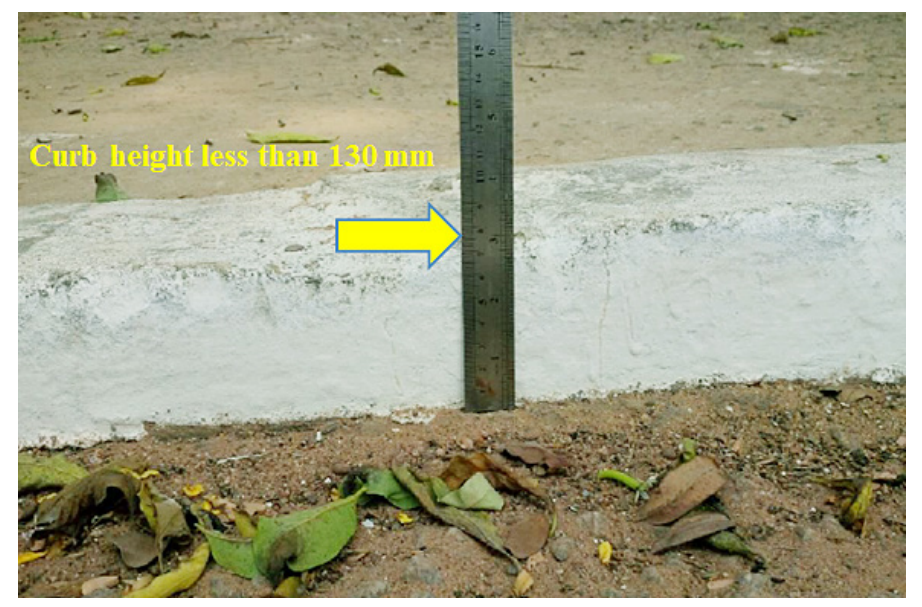

Source: Fieldwork, 2016

Plate 5: Dislodged bricks on the Sasakawa road

Though Hoy (2004) calls for a higher curb to ensure and sustain the safety of travellers with disability, the UNDP further calls for an accompanying curb cut or drop curb to facilitate the movement of wheelchair and visually impaired users in accessing these sidewalks. In simple terms, curb cuts are to be placed at points where one would have to transit from the road to the sidewalk or vice versa, and without this facility, a wheelchair user would find it extremely difficult to join the sidewalks if such respondent is travelling alone. Even if there is an accompaniment, the efforts required to join the sidewalks may compel wheelchair users to resort to the use of the road. The absence of drop curbs at various points of intersection between the sidewalks and road as represented by the blue arrow in Plate 6 results in a total abandonment of sidewalks by students in wheelchairs, thereby resorting to the road as a better alternative. For commuters on the sidewalk with the yellow arrow, the presence of the drop curb would easily facilitate the transition of a wheelchair user from the road to the sidewalk and vice versa.

A discussion with a male wheelchair user on the use of pavement without curb cuts at the North Campus revealed that:

"It is not easy! You need someone to assist you to get to the pavement. The edge of the pavement is not flat where I can easily pull my wheelchair onto the pavement so I need someone to assist me to get on the pavement. Most of the time people help me but for me in particular, I don't depend much on people's assistance. You see, in the University of Cape Coast, it's believed that everyone is busy so when they are going, I think they are busy so I don't bother to ask other commuters for assistance in getting on to the sidewalk. ........... while using the road instead of the pavement" 


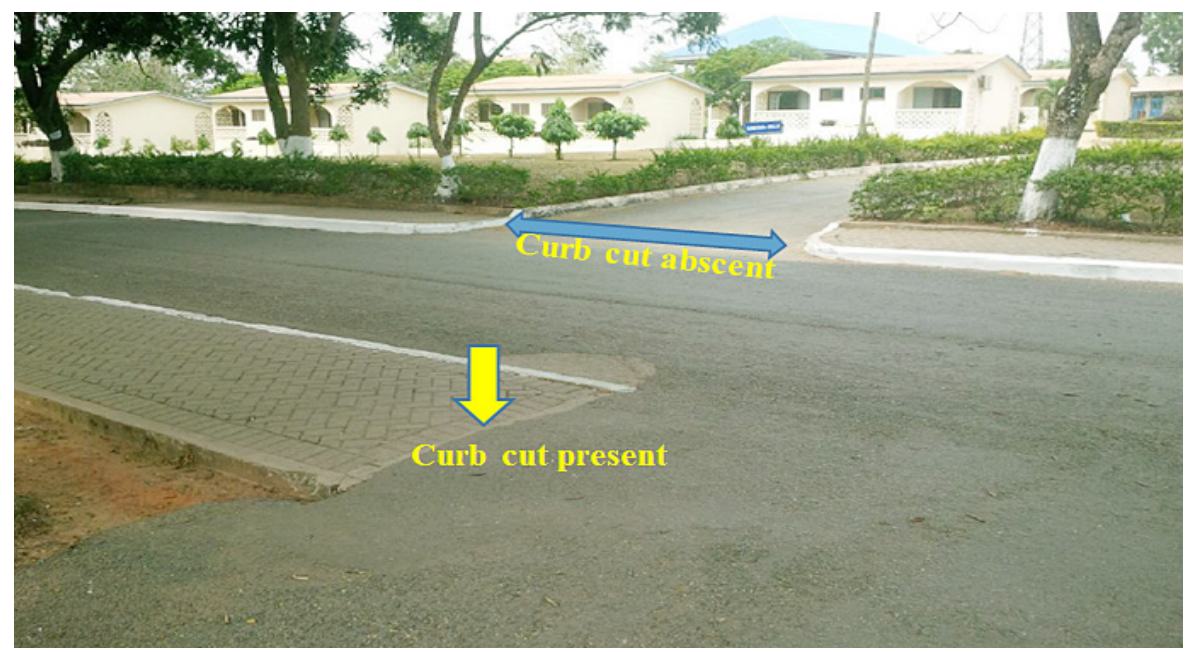

\section{Source: Fieldwork, 2016}

Plate 6: Curb cut present at the yellow arrow and no curb cur at the blue arrow

\section{Crossing Aids}

Crossing aids refer to road furniture that facilitates the safe crossing of a road by pedestrians. These include traffic light, Zebra crossing and pedestrian island for highways. In addition to the identified, complementary facilities like curb cuts, wider and clear pavements are also needed to ensure safe crossing. According to Adjei (2013), these facilities are needed to control the movements of all road users since travellers with disability react slowly to danger and other unexpected situations than their abled counterparts.

The first facility under review is the presence of zebra crossing that clearly outlines pedestrians' right of way. Frye (2013) recommends that controlled crossing points should always have Zebra crossings that are perpendicular to the drop curbs at the point of crossing. This means that the width of the zebra crossing should at least be the same as the width of the floor of the curb drop at that crossing point. From data collected, only four zebra crossings were observed on campus, and out of this number, three had no drop curbs, making it extremely difficult for wheelchair users to transit from the sidewalk to cross the street. These zebra crossings can be located at the shuttle station and the junction close to the Faculty of Education Lecture Theatre.
Being the only zebra crossing with an accompanying drop curb, the position of the zebra crossing in relation to the drop curbs on the University Avenue was observed to be misaligned. As seen in Plate 7, the student with disability will have to move about 3 metres into the road, if he or she would want to access the zebra crossing. Moving about 3 metres into the road to access the zebra crossing increases the risk of injury or accident for wheelchair users and the visually impaired since they are slower in responding to a danger that may befall them (ECMT, 2006). This misalignment can be found on both sides of the road and the danger here could be the risk of being knocked down by a vehicle or slipping.

For the safety of students with disabilities who cross streets with more than two lanes, the presence of the Traffic Island also guarantees some degree of safety, since it reduces the number of lanes to be crossed at a time. Instead of crossing a 4-lane highway at once, the pedestrian island is positioned in between the 4-lane highway. This implies that the pedestrian would have to cross the first 2 lanes, stay in a safe zone and cross the other 2 lanes when it is safe to do so. For travellers with disability, the Americans with Disability Act recommends that the pedestrian island should be in a dip and of the same level as 
the adjoining road (as seen in Plate 7) since this would easily guarantee easy crossing for wheelchair users (United States Congress, 2009). Also, the width of the traffic island should be wide enough to accommodate at least a wheelchair user and a non-wheelchair user.

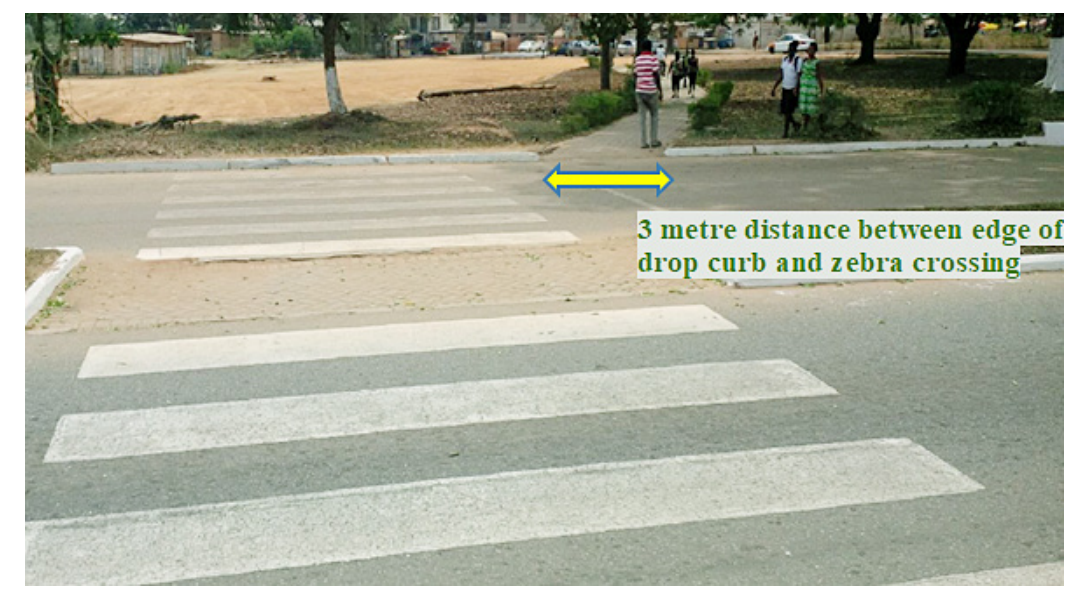

Plate 7: Zebra crossing beside the Main Library

\section{Source: Fieldwork, 2016}

The only 4-lane road on campus is the University Avenue which connects University East Gate to the Science Faculty at the North Campus. Only two pedestrian islands were observed on this route. While the first pedestrian island (Plate 7) meets the dictates of the UNDP, the second island does not. With its proximity to a high pedestrian traffic area, the second pedestrian island (as seen in Plate 8) has no zebra crossing linking the adjoining streets, neither does it have complimentary drop curbs on both sides of the sidewalk. Also, the island was observed to be on the same level as the adjoining pavement instead of being in a dip. These conditions make it extremely difficult for wheelchair users to access the island. Additionally, the study further identified this crossing point as the least preferred by wheelchair users on campus.

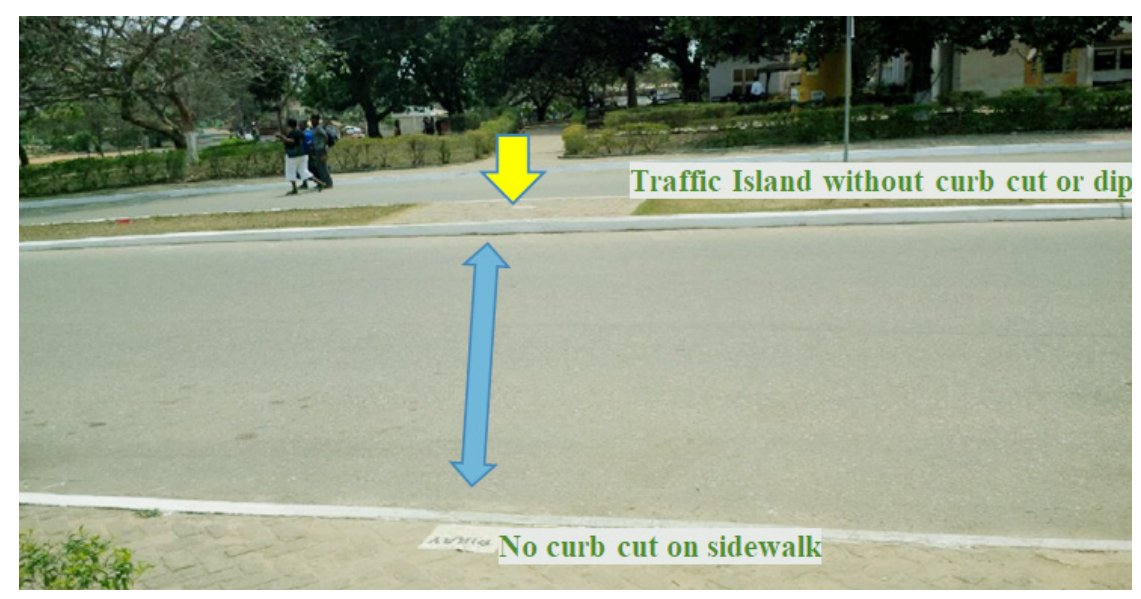

Plate 8: Traffic Island without zebra crossing and drop curbs when approaching the Science Faculty

Source: Fieldwork, 2016 


\section{Conclusion}

The condition of the pedestrian infrastructure hinders exclusive and independent usage of sidewalks on campus. With reference to independence, students with disability in the University of Cape Coast would still have to depend on students without disability for assistance in navigating walkways on campus. The presence of potholes and path obstructing objects, further exposes these students to the risk of injuries, since the visually impaired students stand the risk of bumping into these objects unless they walk with an aid. For wheelchair users, the absence of curb cuts on most sections of the sidewalk does not promote exclusive usage of the sidewalk by since they may find it difficult to transit from the road to the sidewalk and vice versa. Further, the alignment of the pedestrian island, curb cuts and zebra crossing have also been identified to expose students to the risk of vehicular crashes since current road furniture in some part of campus did not seem to follow the dictates of the UNDP. The study recommends an overhauling of the current walking environment as well as enforcement of state and international policy regarding the development of an inclusive environment.

\section{Acknowledgements}

This paper is extracted from a Master of Philosophy thesis prepared by Prince Kwame Odame at the Department of Geography and Regional Planning at the University of Cape Coast. A special thank you goes to all students with physical disability who took time to offer the needed information for this study. My appreciation also goes to my supervisors Prof Albert M. Abane, Dr Edem Ameumey and Ms. Antoinette Ama Rhule who served as my research assistant.

\section{Funding}

The study was funded by the corresponding author and did not receive any external funding source.

\section{Conflict of interest}

No potential conflict of interest was reported by the researchers.

\section{Reference}

1. Adam, I. (2019). Drivers of physical accessibility among hotels Drivers of physical accessibility among hotels. Anatolia, 00(00), 1-12. https:// doi.org/10.1080/13032917.2019.1651356.

2. Adams, M. S. (2012). Assing The Propsects And Challenges of Public Private Partnership In The Provision of Public Transport Service In Ghana: A Case Study Of Metro Mass Transit Company Limited (Kwame Nkrumah University of Science and Technology). Retrieved from http://ir.knust. edu.gh/bitstream/123456789/7618/1/MOHA MMED\%2BSAANI\%2BADAMS\%2B1\%2Bau gust.pdf.

3. Addo, G. (2014). Analysis of barriers to children with mobility impairment in basic education in Accra metropolis (Kwame Nkrumah University of Science and Technology). Retrieved from http://citeseerx.ist.psu.edu/viewdoc/downloa d?doi=10.1.1.868.2719\&rep=rep1\&type=pdf.

4. Adjei, D. N. N. (2013). Putting decision into action : The Disability Act of Ghana, six years down the line. (University of Bergen). Retrieved from https://pdfs.semanticscholar.org/eeb2/ de62e9ae941ee472510f892f7be9af9463ef.pdf.
5. Amoako-Sakyi, R. (2016). School path walkability and pedestrain crashes in the Cape Coast Metropolitan area. University of Cape Coast.

6. Anastasiou, D., \& Kauffman, J. M. (2013). The social model of disability: Dichotomy between impairment and disability. Journal of Medicine and Philosophy (United Kingdom), 38(4), 441-459. https://doi.org/10.1093/jmp/jht026

7. Ashigbi, K. E. Y., Danso, A. K., Tudzi, E. P., \& Torgbenu, E. L. (2017). Mobility challenges of persons with disabilities in a university in ghana. Journal of Disability Studies, 3(1), 12-18.

8. Ashigbi, Y., Danso, A. K., Dogbevi, E. K., \& Owusu Dabo, E. (2013). Limitations to Mobility of Students With Special Needs : A Case Study of the of the University of Ghana, Legon. $6^{\text {th }}$ Ghana Biomed 2013 At: University of Cape Coast. https://doi.org/10.13140/2.1.1576.1601. Bezyak, J. L., Sabella, S. A., \& Gattis, R. H. (2017). Public Transportation: An Investigation of Barriers for People With Disabilities. Journal of Disability Policy Studies, 28(1), 52-60. https:// doi.org/10.1177/1044207317702070. 
9. Brown, B. B., Werner, C. M., Amburgey, J. W., \& Szalay, C. (2007). Walkable Route Perceptions and Physical Features. Environment and Behavior, 39(1). Retrieved from doi:10.1177/0013916506295569.

10. Danso, A.K, Atuahene, B. ., \& Agyekum, K. (2017). Assessing the accessibility of built infrastructure facilities for persons with disabilities : A case of the Sofoline Interchange. (April), 535-547.

11. Danso, Anthony K, Ayarkwa, J., \& Dansoh, A. (2009). State of accessibility for the disabled in selected monumental public buildings in Accra, Ghana. The Ghana Surveyor.

12. Danso, Anthony Kwame, Ashigbi, Y. E., \& Tudzi, E. P. (2014). Mobility challenges of Persons Living With Disabilities at the University of Ghana. $1^{\text {st }}$ International Conference on Applied Science and Technology (ICAST 2014), 47.

13. ECMT. (2006). Improving transport accessibility for all: guides to good practice. Retrieved from http://www.scandichotels.com/Always-atScandic/Special-needs

14. Eseta, T. (2017). Transport Problems of People with Disabilities and Its Policy Issues : Cases in Addis Ababa. Addis Ababa University.

15. Ferreira, M. A. G., \& Sanches, S. da P. (2007). Proposal of a sidewalk accessibility index. Journal of Urban and Environmental Engineering, 1(1), 1-9. https://doi.org/10.4090/ juee.2007.v1n1.001009.

16. Frye, A. (2013). Disabled and Older Persons and Sustainable Urban Mobility. 1. Retrieved from http://unhabitat.org/wp-content/ uploads/2013/06/GRHS.2013.Thematic. Disabled.and_.Older_.Persons.pdf.

17. Ghana Statistical Service. (2014a). Disability in Ghana: Population and Housing Census.

18. Ghana Statistical Service. (2014b). Population and Housing census report - Disability in Ghana.

19. Government of Ghana. Persons with disability. , (2006).

20. Green, R. J. (2011). An introductory theoretical and methodological framework for a universal mobility index (UMI) to quantify, compare, and longitudinally track equity of access across the built environment. Journal of Disability Policy Studies, 21(4), 219-229. https://doi. org/10.1177/1044207310384998.

21. Haegele, J. A., \& Hodge, S. (2016). Disability
Discourse: Overview and Critiques of the Medical and Social Models. Quest, 68(2), 193-206. https://doi.org/10.1080/00336297.2 016.1143849.

22. Hoy, S. (2004). City of Toronto Accessibility Design Guidlines. Retrieved from https:// webcache.googleusercontent.com/search?q=c ache:cQdHVFFPjO4J:https://assets.publishing. service.gov.uk/government/uploads/system/ uploads/attachment_data/file/7776/156681. $p d f+\& c d=1 \& h l=e n \& c t=c l n k \& g l=g h$.

23. Lang, R. (2007). The development and critique of the social model of disability. London: 1-36. Retrieved from www.ucl.ac.za/lc-ccr/ centrepublications/workingpapers.

24. Litman, T. (2019). Evaluating accessbilty of trnasport planning: Measuirng people's ability to reach desired goods and services. Victoria Transport Policy Institute.

25. Mantey, E. E. (2014). Accessibility to inclusive education for children with disabilities: a case of two selected areas in Ghana (University of Siegen; Vol. 2). Retrieved from https://d-nb. info/1068362936/34.

26. McNulty, T. (2003). Planning and access for disabled people: A good practice guide. Retrieved from https://www.gov.uk/government/ uploads/system/uploads/attachment_data/ file/7776/156681.pdf.

27. Mitchell, C., \& Rickert, T. (2010). Review of International Best Practice in Accessible Public Transportation for Persons with Disabilities. In UNDP. Retrieved from http://www.my.undp. org/content/malaysia/en/home/library/poverty/ PubPovRed_PublicTransportation.html

28. Nyangweso, M. (2018). Disability in Africa : A Cultural / Religious Perspective. Peace, Human Rights Governance (PHRG), (June). Retrieved from https://www.researchgate.net/ publication/325642373_Disability_in_Africa_A_ CulturalReligious_Perspective.

29. Ocran, J. (2019). Exposing the protected: Ghana's disability laws and the rights of disabled people. Disability and Society, 34(4), 663668. https://doi.org/10.1080/09687599.2018. 1556491.

30. Odame, P. K. (2017). Road transport infrastructure and mobility : Views of students with physcial disability in the University of Cape Coast (University of Cape Coast). 
Retrieved from https://erl.ucc.edu.gh/jspui/ handle/123456789/3211.

31. Tudzi, E. P., Bugri, J., \& Danso, A. K. (2017). Towards Accessible Built Environments in Universities in Ghana: An Approach to Inclusiveness Assessment. Disability, CBR \& Inclusive Development, 28(1), 189-206. https:// doi.org/10.5463/dcid.v1i1.592.

32. United Nations. (2006). Convention on the Rights of Persons with Disabilities. In United Nations (Vol. 49). https://doi.org/10.1057/ palgrave.development. 1100310.

33. United Nations Educational Social and
Cultural Organisation (UNESCO). (1994). The Salamanca Statement and Framework for Action. Policy, (June), 7-10.

34. United States Congress. (2009). Americans with disability Act of 1990 (Vol. 2). Retrieved from https://webcache.googleusercontent. com/search? q=cache:6q0Fv5SkYBUJ :https://www.ada.gov/pubs/adastatute08. $p d f+\& c d=1 \& h l=e n \& c t=c l n k \& g l=g h$.

35. University of Cape Coast. (2016). About the University of Cape Coast. Retrieved from https:// ucc.edu.gh/main/about/history. 